\title{
Ticks infesting humans in Italy and associated pathogens
}

\author{
Domenico Otranto ${ }^{1 *}$, Filipe Dantas-Torres ${ }^{1,2}$, Alessio Giannelli ${ }^{1}$, Maria Stefania Latrofa ${ }^{1}$, Antonio Cascio ${ }^{3}$, \\ Stefania Cazzin ${ }^{4}$, Silvia Ravagnan ${ }^{4}$, Fabrizio Montarsi ${ }^{4}$, Sergio Aurelio Zanzani ${ }^{5}$, Maria Teresa Manfredi ${ }^{5}$ \\ and Gioia Capelli ${ }^{4}$
}

\begin{abstract}
Background: Ticks may transmit a large variety of pathogens, which cause illnesses in animals and humans, commonly referred to as to tick-borne diseases (TBDs). The incidence of human TBDs in Italy is underestimated because of poor surveillance and the scant amount of studies available.

Methods: Samples ( $n=561$ ) were collected from humans in four main geographical areas of Italy (i.e., northwestern, northeastern, southern Italy, and Sicily), which represent a variety of environments. After being morphologically identified, ticks were molecularly tested with selected protocols for the presence of pathogens of the genera Rickettsia, Babesia, Theileria, Candidatus Neoehrlichia mikurensis, Borrelia and Anaplasma.

Results: Ticks belonged to 16 species of the genera Argas, Dermacentor, Haemaphysalis, Hyalomma, Ixodes and Rhipicephalus, with /xodes ricinus (59.5\%) being the species most frequently retrieved, followed by Rhipicephalus sanguineus sensu lato (21.4\%). Nymphs were the life stage most frequently retrieved (41\%), followed by adult females (34.6\%). The overall positivity to any pathogen detected was 18\%. Detected microorganisms were Rickettsia spp. (17.0\%), Anaplasma phagocytophilum (0.8\%), Borrelia afzelii (0.5\%), Borrelia valaisiana (0.3\%), C. N. mikurensis (0.5\%) and Babesia venatorum (0.6\%).
\end{abstract}

Conclusions: Results indicate that people living in the Italian peninsula are at risk of being bitten by different tick species, which may transmit a plethora of TBD causing pathogens and that co-infections may also occur.

Keywords: Ticks, Pathogens, Humans, Tick-borne diseases, Italy, Distribution

\section{Background}

Ticks are amongst the most important arthropod parasites of animals and display a worldwide distribution, being adapted to different environments and climates and host species [1]. Hard ticks (order Ixodida, family Ixodidae) represent the most diverse group, occurring in tropical, temperate and even arctic regions [2]. Their medical and veterinary importance is mostly due to their great capacity of transmitting viral, bacterial, protozoan and helminthic infections to animals, which may cause a diverse range of affections, commonly referred to as tick-borne diseases (TBDs). Importantly, zoonotic TBDs (e.g., anaplasmosis, babesiosis, borreliosis, rickettsioses and tick-borne encephalitis) may be associated with both domestic and wild

\footnotetext{
*Correspondence: domenico.otranto@uniba.it

'Department of Veterinary Medicine, University of Bari, 70010 Valenzano, Bari, Italy

Full list of author information is available at the end of the article
}

animals, with a high risk of acquiring infections for humans frequenting tick-infested areas, such as forests, meadow habitats and grasslands $[1,3,4]$.

In spite of the availability of several chemical options for tick control, especially for companion animals and livestock, the incidence of human TBDs is increasing worldwide $[1,5]$. For example, cases of Lyme borreliosis by Borrelia burgdorferi sensu lato are on the rise in the United States, and are related to the occurrence of its competent vector Ixodes scapularis. In Europe there is an estimated average of 85,000 cases per year [6]. The development of molecular tools (e.g., reverse-line blotting hybridization, pyrosequencing and next generation sequencing), has refined the current understanding of the distribution of TBDs and the role of certain tick species as vectors of these pathogens [1]. Importantly, the immediate removal of an attached tick, referral to a qualified physician and tick identification in specialized laboratories, 
is pivotal to prompt the diagnosis and the treatment of any TBDs. In addition, the set-up of surveillance programs is required for understanding the risks of transmission of specific infections in certain areas [1].

With about 40 species [7], the tick fauna in Italy is one of the most diverse across Europe, with more species than countries such as Portugal [8] and the United Kingdom $[9,10]$. For example, a recent study confirmed a high species richness and abundance of free-living ticks in southern Italy, with up to nine species (i.e., Dermacentor marginatus, Haemaphysalis concinna, Haemaphysalis inermis, Haemaphysalis parva, Haemaphysalis sulcata, Hyalomma marginatum, Ixodes ricinus, Rhipicephalus bursa and Rhipicephalus turanicus) collected in a single forested area [11]. Conversely, the species richness in the environment is lower in central and northern Italy where I. ricinus is the most prevalent species [12-14].

The incidence of TBDs in humans in Italy is underestimated because of low rates of notification of cases and scant studies focussing on the detection of pathogens in ticks collected from humans (e.g., ref. [15]). Accordingly, the limited data on ticks, and their associated pathogens infecting humans in Italy may impair the understanding of the risk for TBDs in this country. This aspect is particularly important considering that the Italian peninsula has a great vocation for tourism, mostly during the spring and summer months, which constitute the high-risk period for tick infestation in some areas.
Therefore, the present study aimed to identify the species of ticks removed from humans living in northern, southern and insular Italy, and to molecularly detect associated pathogens.

\section{Methods}

\section{Tick collection and identification}

Ticks were collected from humans at different time points, from 1995 to 2011, in northwestern (Savona, Liguria region; site 1), northeastern (Trentino-Alto Adige, Veneto and Friuli Venezia Giulia regions; site 2), southern Italy (Apulia and Basilicata regions; site 3) and Sicily island (site 4) (Figure 1). These sites included four main geographical areas of Italy, representing a variety of natural environments. Most of the inland northern areas are featured by a continental humid climate, whereas the coastal areas of the Liguria region and most of the peninsula are characterized by a Mediterranean temperate climate, with mild winters and hot summers $[2,4,7]$.

All specimens were placed in vials containing 70\% ethanol and sent to the laboratories of the Department of Veterinary Medicine of the University of Bari (i.e., ticks from site 3 and 4), University of Milano (i.e., ticks from site 1) and to the Istituto Zooprofilattico Sperimentale delle Venezie (i.e., ticks from site 2). Species identification was performed using taxonomic keys appropriate for each developmental stage (i.e., larvae, nymphs, females, and males) $[7,15]$.

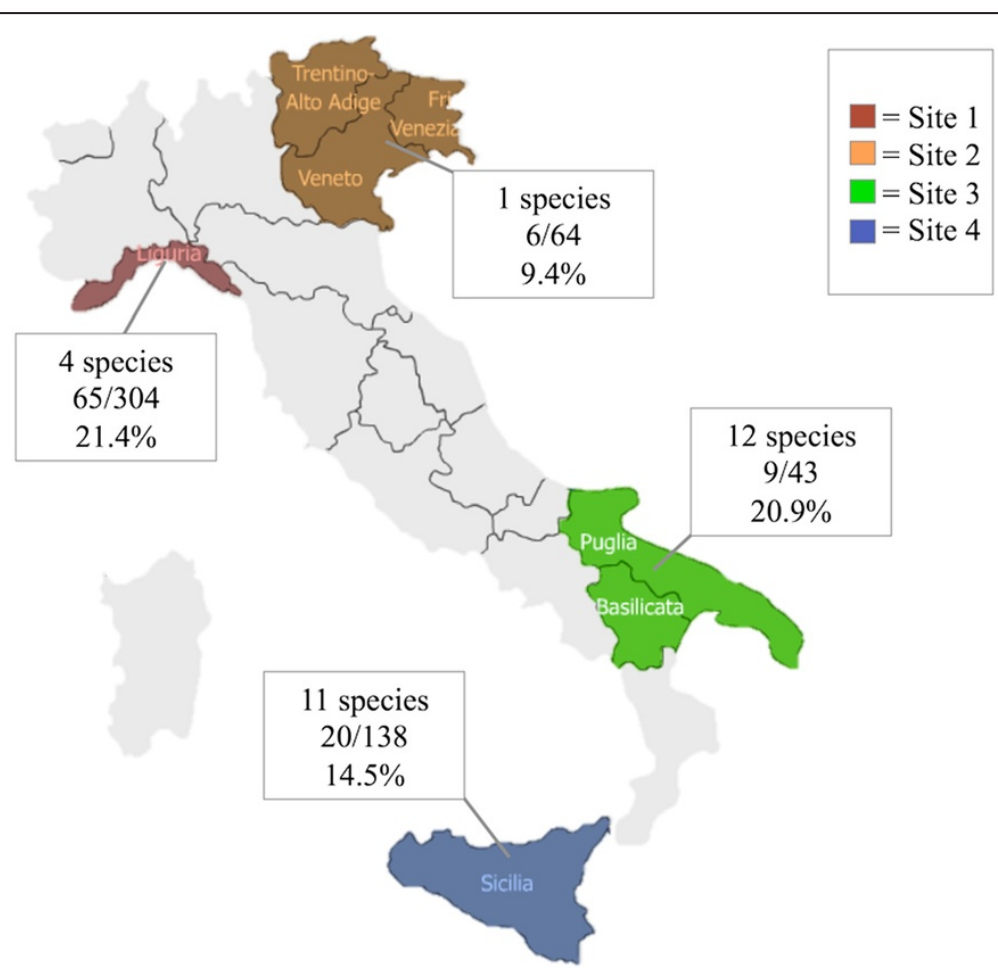

Figure 1 Sampling areas and number of positive specimens collected from each site across the Italian peninsula. 


\section{Amplification of pathogen DNA}

All ticks were tested for the presence of pathogens of the genera Rickettsia, Babesia, Theileria as well as of Candidatus Neoehrlichia mikurensis. In addition, Ixodes ticks were screened for B. burgdorferi s.l. and Anaplasma phagocytophilum.

DNA was extracted from individual adults, nymphs or larvae, using the All Prep DNA/RNA mini Kit (Qiagen, Inc., Valencia, CA), according to the manufacturer's instructions, and then frozen at $-20^{\circ} \mathrm{C}$.

Target genes, primers and probes used, along with the methodologies employed for testing each pathogen, are listed in Table 1. Pathogen identity was confirmed by sequencing each amplicon, using a 16-capillary ABI PRISM $3130 \times 1$ Genetic Analyzer (Applied Biosystem, Foster City, CA, USA). Sequence data were assembled and edited with SeqScape software v 2.5 (Applied Biosystem,
Foster City, CA, USA), aligned and finally compared with representative sequences available in GenBank.

\section{Statistical analysis}

The difference in prevalence of different tick and pathogen species, according to their provenance and tick life stages were tested using the chi-square test and the Fisher's exact test, when appropriate. GraphPad statistical software (GraphPad Software, Inc; www.graphpad.com/ quickcalcs/contingency1/) was used. Differences were considered significant at $\mathrm{p}<0.05$.

\section{Ethics statement}

Following the patients' informed consent, ticks were collected by physicians working at the first aid guard and sent, for diagnostic purposes, to the reference laboratories (see above). As this study was based on tick identification

Table 1 Molecular detection of tick-borne pathogens: PCR methods, target genes, primers, nucleotide sequences, amplicon size (base pairs)

\begin{tabular}{|c|c|c|c|c|c|c|}
\hline Species & PCR method & $\begin{array}{l}\text { Target } \\
\text { gene }\end{array}$ & Primer & Nucleotide sequence $\left(5^{\prime}-3^{\prime}\right)$ & $\begin{array}{l}\text { Amplicon } \\
\text { size (bp) }\end{array}$ & Reference \\
\hline \multirow[t]{5}{*}{ Anaplasma phagocytophilum } & duplex RT-PCR & msp2 & ApMSP2f & ATGGAAGGTAGTGTTGGTTATGGTATT & 77 & {$[16]$} \\
\hline & & & ApMSP2r & TTGGTCTTGAAGCGCTCGTA & & \\
\hline & & & ApMSP2p & TGGTGCCAGGGTTGAGCTTGAGATTG & & \\
\hline & PCR & msp2 & msp2-3f & CCAGCGTTAGCAAGATAAGAG & 334 & {$[17]$} \\
\hline & & & msp2-3r & GMCCAGTAACAACATCATAAGC & & \\
\hline \multirow[t]{3}{*}{ Babesia/Theileria spp. } & RT-PCR Sybr green & $18 \mathrm{~S}$ rRNA & NM-1152as & TTCTACTTTGAACATTTGAAGAATTACTAT & $411-452$ & {$[18]$} \\
\hline & & & BJ1 & GTCTTGTAATTGGAATGATGG & & \\
\hline & & & BN2 & TAGTTATGGTTAGGACTACG & & \\
\hline \multirow{5}{*}{$\begin{array}{l}\text { Borrelia burgdorferi } \\
\text { sensu lato }\end{array}$} & duplex RT-PCR & 235 rRNA & $\mathrm{Bb} 23 \mathrm{Sf}$ & CGAGTCTTAAAAGGGCGATTTAGT & 75 & {$[16]$} \\
\hline & & & $\mathrm{Bb} 23 \mathrm{Sr}$ & GCTTCAGCCTGGCCATAAATAG & & \\
\hline & & & $\mathrm{Bb} 23 \mathrm{Sp}$ & AGATGTGGTAGACCCGAAGCCGAGTG & & \\
\hline & PCR & Flagellin & FLA1 & AGAGCAACTTACAGACGAAATTAAT & 482 & {$[19]$} \\
\hline & & & FLA2 & CAAGTCTATITGGAAAGCACCTAA & & \\
\hline \multirow{5}{*}{$\begin{array}{l}\text { Candidatus Neoehrlichia } \\
\text { mikurensis }\end{array}$} & TaqMan RT-PCR & groEL & NMikGroEL F2a & CCTTGAAAATATAGCAAGATCAGGTAG & 101 & {$[20]$} \\
\hline & & & NMikGroEL R2b & CCACCACGTAACTTATTTAGCACTAAAG & & \\
\hline & & & NMikGroEL P2a & ССТСТACTAATTATTGCTGAAGATGTAGA & & \\
\hline & & & & AGGTGAAGC & & \\
\hline & PCR & groEL & NM-128 s & AACAGGTGAAACACTAGATAAGTCCAT & 1024 & {$[21]$} \\
\hline \multirow[t]{9}{*}{ Rickettsia spp. } & TaqMan RT-PCR & gltA & CS5 & GAGAGAAAATTATATCCAAATGTTGAT & 146 & {$[22]$} \\
\hline & & & CS6 & CATTGTGCCATCCAGCCTACGGT & & \\
\hline & & & Probe CS5-6 & CATTGTGCCATCCAGCCTACGGT & & \\
\hline & PCR & gltA & RpCS.877p & GGGGGCCTGCTCACGGCGG & 381 & {$[23]$} \\
\hline & & & $\operatorname{RpCS1258n}$ & ATTGCAAAAAGTACAGTGAACA & & \\
\hline & PCR & ompA & $\operatorname{Rr} 190.70 p$ & ATGGCGAATATTTCTCCAAAA & 532 & {$[24]$} \\
\hline & & & $\operatorname{Rr} 190.602 n$ & AGTGCAGCATTCGCTCCCCCT & & \\
\hline & PCR & ompB & rompB OFm & GTAACCGGAARTAATCGTTCGT & 489 & [25] (modified) \\
\hline & & & rompB ORm & GCTITATAACCAGCTAAACCRCC & & \\
\hline
\end{tabular}


and pathogen detection in ticks, thus not requiring any involvement of patients, ethical approval was not needed.

\section{Results}

In total, 561 ticks were identified, including 16 species belonging to the genera Argas, Dermacentor, Haemaphysalis, Hyalomma, Ixodes and Rhipicephalus (Table 2). The tick species most commonly retrieved were I. ricinus (59.5\%), followed by $R h$. sanguineus s.l. (21.4\%), H. lusitanicum (5\%) and D. marginatus (4.5\%) (Table 2). The life stage most frequently collected were nymphs (41\%) and females (34.6\%), followed by males (13.4\%) and larvae (8.4\%) (Table 3).

The overall positivity of samples to any pathogen was $18 \%$, with prevalence rates ranging from $9.4 \%$ in northeastern Italy to $21.4 \%, 20.9 \%$ and $14.5 \%$ in northwestern, southern Italy and Sicily, respectively. The ixodid species most frequently positive for any pathogen was $D$. marginatus (48\%), followed by I. ricinus (21\%), Rh. sanguineus s.l. (10.8\%) and H. lusitanicum (3.7\%) (Table 2). Also Rh. turanicus ticks were infected (28.6\%), but only seven specimens were collected and tested.

A total of 14 microorganism species were identified, most belonging to the genus Rickettsia (17.0\%), namely Rickettsia

\begin{tabular}{|c|c|}
\hline Tick species (n) & No. of positive $(\%)^{*}$ \\
\hline Argas reflexus (2) & 0 \\
\hline Dermacentor marginatus (25) & $12(48.0)^{\mathrm{ABC}}$ \\
\hline Haemaphysalis inermis (1) & 1 \\
\hline Haemaphysalis parva (2) & 0 \\
\hline Haemaphysalis punctata (2) & 0 \\
\hline Hyalomma detritum detritum (2) & 0 \\
\hline Hyalomma lusitanicum (27) & $1(3.7)^{\mathrm{Ad}}$ \\
\hline Hyalomma marginatum (2) & 0 \\
\hline Hyalomma spp. (8) & 0 \\
\hline Ixodes acuminatus (2) & 0 \\
\hline Ixodes ventalloi (1) & 1 \\
\hline Ixodes ricinus (334) & $70(21.0)^{\text {Bde }}$ \\
\hline Ixodes spp. (8) & 0 \\
\hline Rhipicephalus bursa (4) & 0 \\
\hline Rhipicephalus pusillus (1) & 0 \\
\hline Rhipicephalus sanguineus s.l. (120) & $13(10.8)^{C e}$ \\
\hline Rhipicephalus sp. (1) & 0 \\
\hline Rhipicephalus turanicus (7) & $2(28.6)$ \\
\hline Not determined (12) & $1(8.3)$ \\
\hline Total (561) & $101(18.0)$ \\
\hline
\end{tabular}

$\left.{ }^{*}\right)$ Statistically significant differences are marked by equal letters (uppercase letters $=p<0.01$; lowercase letters $=p<0.05$ ).
Table 3 Number and percentage of tick stages retrieved and their positivity for one or more pathogens

\begin{tabular}{lcc}
\hline Life stage & $\mathbf{N}^{\circ}(\%)^{*}$ & Positive (\%) \\
\hline Females & $194(34.6)^{\mathrm{AB}}$ & $35(18.0)$ \\
Males & $75(13.4)^{\mathrm{ACD}}$ & $18(24.0)$ \\
Larvae & $47(8.4)^{\mathrm{BCE}}$ & $6(12.8)$ \\
Nymphs & $230(41.0)^{\mathrm{DE}}$ & $41(17.8)$ \\
Not determined & $15(2.1)$ & $1(0.6)$ \\
\hline
\end{tabular}

(*) Statistically significant differences are marked by equal letters (uppercase letters $=p<0.01$; lowercase letters $=p<0.05$ ).

monacensis (10.1\%), R. massiliae (2.1\%), R. slovaca (1.8\%), R. helvetica (1.4\%), and Rickettsia spp. (0.5\%) (Table 4). Other pathogen species were A. phagocytophilum (0.8\%), Borrelia afzelii $(0.5 \%)$ and B. valaisiana (0.3\%), C. N. mikurensis $(0.5 \%)$ and $B$. venatorum $(0.6 \%)$. The pathogen association in different tick species ranged from two up to eight infectious agents (i.e., in I. ricinus). While Ixodes spp. harboured C. N. mikurensis, Anaplasma and Babesia spp., $D$. marginatus was the principal carrier of $R$. slovaca, whereas $R h$. sanguineus s.l. ticks were positive for $R$. massiliae. Co-infections were detected in four I. ricinus ticks, namely A. phagocytophilum/Rickettsia spp. (1 nymph), $R$. monacensis/B. venatorum (1 nymph, 1 female), and $R$. helvetica/B. afzelii (1 nymph).

Tick-borne pathogens were detected in adult specimens of each ixodid species herein identified, with the exception of I. ricinus nymphs and larvae. In particular, I. ricinus larvae were infected by $R$. monacensis. Higher tick species variability was found in sites 3 and 4 compared to the northern regions, where, in contrast, ticks carried a larger number of pathogens (Table 5).

\section{Discussion}

Results of this study indicate that people living in the Italian peninsula are at risk of being bitten by different tick species, which may transmit a plethora of microorganisms. The chance of coming into contact with infected ticks is largely dependent upon the environment and the presence of appropriate hosts, and on whether the ticks or the vertebrate hosts act as reservoirs of the infection [26]. In countries like Italy, characterized by a variety of ecological and climatic characteristics, as well as different regional human habits, the distribution pattern of human TBDs varies greatly from north to south [27]. However, the large number of ticks collected from Sicily and northwestern Italy, compared to the other sampling sites, is most likely due to the convenience sample size here examined. For example, finding $I$. ricinus and $R h$. sanguineus s.l. as the species most frequently detected on humans in northern and southern Italy, respectively, is not surprising. Indeed, I. ricinus ticks show a high affiliation to woodland areas of north-eastern and 
Table 4 Number and percentage of ticks positive for different pathogen species

\begin{tabular}{|c|c|c|}
\hline Pathogen ( $\mathrm{n}$. of examined ticks) & Positive (\%) & GenBank Accession numbers (gene) \\
\hline Rickettsia spp. (554) & $3(0.5)$ & - \\
\hline R. monacensis (554) & $56(10.1)$ & KJ663734, KJ663735, KJ663744 (gltA) \\
\hline R. slovaca (554) & $10(1.8)$ & KJ663736, KJ663743 (gltA), KJ663756 (ompB) \\
\hline R. helvetica (554) & $8(1.4)$ & KJ663739, KJ663745 (g/tA), KJ663750 (ompB) \\
\hline R. peacockii (554) & $1(0.2)$ & KJ663738(gltA), KJ675444 (ompA), KJ675443 (ompB) \\
\hline R. raoulti (554) & $1(0.2)$ & KJ663737 (gltA), KJ663752 (ompB) \\
\hline R. aeschilmannii (554) & $2(0.4)$ & KJ663742 (gltA), KJ663748(ompA), KJ663755 (ompB) \\
\hline R. massiliae (554) & $12(2.1)$ & $\begin{array}{l}\text { KJ663740, KJ663741 (gltA), KJ663746, KJ663747, } \\
\text { KJ663749 (ompA), KJ663751, KJ663753, KJ663754 (ompB) }\end{array}$ \\
\hline R. massiliae/ripicephali (554) & $1(0.2)$ & - \\
\hline Total Rickettsiae (554) & $94(17.0)$ & \\
\hline Anaplasma phagocytophilum (372) & $3(0.8)$ & KJ663729 \\
\hline Borrelia afzelii (371) & $2(0.5)$ & KJ663732 \\
\hline B. valaisiana (371) & $1(0.3)$ & - \\
\hline Babesia venatorum (509) & $3(0.6)$ & KJ663730 \\
\hline C. N. mikurensis (433) & $2(0.5)$ & KJ663733 \\
\hline
\end{tabular}

northwestern Italy, where this species finds optimal conditions, in terms of temperature (i.e., $20-23^{\circ} \mathrm{C}$ ) and relative humidity (i.e., 85-98\%) for its development $[28,29]$. Conversely, $R h$. sanguineus s.l. develops at higher temperatures (e.g., $20-35^{\circ} \mathrm{C}$ ) and variable relative humidity (e.g., 35-95\%) [30]. Although the latter species feeds preferentially on dogs, it can also feed readily on people [31]. Moreover, A. reflexus, Rh. turanicus, $H$. lusitanicum, $H$. marginatum and $D$. marginatus have been reported on humans, displaying an anthropophilic feeding behaviour, in the absence of their main vertebrate host [26,32,33]. In contrast, the occurrence of other ixodids on humans (Table 2) is unlikely. Indeed, differently from hunting ticks (e.g., Hyalomma spp.), which actively seek for their hosts in the environment, Ixodes and Haemaphysalis species adopt an ambush strategy, waiting on a blade of grass, leaves or shrubs for animals to pass by, attaching upon contact with the host [34]. In addition, although some tick species display a strict host specialization, most ticks are generalists [35] and may therefore parasitize a range of different hosts, including humans.

In spite of their small size, the majority of ticks removed in the present study were nymphs (41\%), which may be easily overlooked $[7,36]$. This data is of interest considering that, in other studies [37], only adults were collected from humans and molecularly processed for pathogens. In addition, the detection of $R$. monacensis in $I$. ricinus larvae, not only suggests its vertical transmission, but also indicates their potential role as vectors for this pathogen.

The incidence of human TBDs increased in Italy over the last decade, with 4,604 clinical cases and 33 deaths documented by the Ministry of Health in the period 1998-2002, mainly in southern and insular regions $[38,39]$. In particular, $R$. monacensis was confirmed to be widespread throughout the country, mainly in association with $I$. ricinus [40]. This bacterium, isolated for the first time in Germany in 2002 [41], is a spotted fever group (SFG) rickettsia, highly prevalent throughout Europe, with rates of infections in Ixodes spp. reaching 34.6\% in some areas [40]. This pathogen has been detected in ticks from northern Italy $[14,42]$, with a lower estimated prevalence (i.e., $3.7-4.5 \%$ ) in $I$. ricinus as compared to the present findings. Importantly, the detection of $R$. monacensis in $D$. marginatus represents a new tick-pathogen association. In spite of the large prevalence of this rickettsia throughout Italy, its pathogenicity is still poorly defined, being referred to as a Mediterranean spotted fever (MSF)-like rickettsia [43], inducing fever, general discomfort, headache, joint pain and erythematous rashes at the site of the tick bite.

The detection of $R$. massiliae in Rh. sanguineus s.l. and $R h$. turanicus from Sicily is in line with data from other Mediterranean countries, including Italy, where the pathogen was found in the same tick species [39]. In addition to fever, acute vision loss, pruritic rash, and tache noire, $R$. massiliae infection may result in eschars on the scalp and neck and lymphadenopathy. This clinical presentation is similar to that caused by $R$. slovaca and $R$. raoultii infections, which are the most prevalent causative agents of tick-borne rickettsioses in Europe after MSF [44,45]. The finding of $R$. slovaca and $R$. raoultii in $D$. marginatus detached from human patients in southern Italy (i.e., site 3 ) is consistent with a previous report in ticks from wild boars in Tuscany (central Italy) [46] and, 
Table 5 Number and percentage of ticks positive for different microorganism species according their regional distribution

\begin{tabular}{|c|c|c|c|}
\hline Region & Species (n) & $\mathbf{N}(\%)^{*}$ & Tick-borne microorganisms (n) \\
\hline Northwestern Italy & D. marginatus (3) & 1 & R. monacensis (1) \\
\hline \multicolumn{4}{|l|}{ (Savona, Liguria) } \\
\hline & I. ricinus (263) & $63(23.9)$ & $\begin{array}{l}\text { R. monacensis (54), A. phagocytophilum (3), B. venatorum (3), } \\
\text { R. helvetica (3), B. valaisiana (1), Rickettsia spp. (1), B. afzelii (1) }\end{array}$ \\
\hline & Ixodes spp. (7) & 0 & \\
\hline & Rh. sanguineus s.l. (31) & $1(3.2)$ & R. slovaca (1) \\
\hline $\begin{array}{l}\text { Northeastern Italy (Veneto, Friuli Venezia } \\
\text { Giulia and Trentino Alto Adige) }\end{array}$ & I. ricinus (64) & $6(9.4)$ & R. helvetica (4), C. N. mikurensis (2), B. afzelii (1) \\
\hline Southern Italy & A. reflexus (2) & 0 & \\
\hline \multirow[t]{11}{*}{ (Puglia and Basilicata) } & D. marginatus (12) & $7(58.3)$ & R. slovaca (5), R. raoulti (1), R. peacockii (1), \\
\hline & H. inermis (1) & 1 & Rickettsia spp. \\
\hline & H. parva (2) & 0 & \\
\hline & H. punctata (1) & 0 & \\
\hline & Hyalomma spp. (4) & 0 & \\
\hline & I. acuminatus (2) & 0 & \\
\hline & I. ricinus (1) & 0 & \\
\hline & I. ventalloi (1) & 1 & R. helvetica (1) \\
\hline & Rh. sanguineus s.l. (15) & 0 & \\
\hline & Rh. turanicus (1) & 0 & \\
\hline & Rhipicephalus spp. (1) & 0 & \\
\hline \multirow[t]{11}{*}{ Sicily } & D. marginatus (10) & 4 & R. slovaca (4) \\
\hline & H. punctata (1) & 0 & \\
\hline & H. d. detritum (2) & 0 & \\
\hline & H. lusitanicum (27) & $1(3.7)$ & R. aeschlimannii (1) \\
\hline & H. marginatum (2) & 0 & \\
\hline & Hyalomma spp. (4) & 0 & \\
\hline & I. ricinus (7) & 1 & R. monacensis (1) \\
\hline & Rh. bursa (4) & 0 & \\
\hline & Rh. pusillus (1) & 0 & \\
\hline & Rh. sanguineus s.l. (74) & $12(16.7)$ & R. massiliae (11), Rickettsia spp. (1) \\
\hline & Rh. turanicus (6) & 2 & R. massiliae (1), R. massiliae/rhipicephali (1) \\
\hline
\end{tabular}

* The prevalence within each tick species is reported only for tick species represented with more than 10 specimens.

for R. slovaca only, in Sicily [47]. The latter confirms the risk posed by this pathogen to humans living on this island, where cases of tick-borne lymphadenopathy syndrome have been recently diagnosed [48]. Finally, $R$. slovaca DNA has been herein amplified for the first time in the only positive specimen of $R h$. sanguineus s.l. from northwestern Italy. In addition, $R$. helvetica DNA was detected in I. ricinus, thus corroborating previous data, reporting a prevalence of the infection in Ixodes spp. ranging from $1.5 \%$ to $50 \%[13,14,42]$. The presence of this SFG rickettsia in northern Italy has been suspected since 2004, when three cases of a mild form of rickettsiosis were serologically attributed to $R$. helvetica [49]. Moreover, the pathogen has been detected in Ixodes ventalloi, a species usually associated with birds in southern Italy, thus raising questions on the role of this tick species as a vector for it [50,51]. Accordingly, birds may play an important role in the maintenance and dissemination of $R$. helvetica in endemic areas [52].

Rickettsia aeschlimannii, a species first isolated from $H$. marginatum from Morocco [53], and then in a patient returning to France from the same country with a MSF-like illness [54], has been detected so far in Hyalomma ticks worldwide [55]. For the Mediterranean area, this bacterium has been found in Hyalomma ticks from Corsica, with an average infection rate of $73.8 \%$ [56], 
as well as in $H$. marginatum from Sardinia [39] and Sicily [47] in $64 \%$ and $20.8 \%$ of the examined specimens, respectively. Therefore, the detection of $R$. aeschlimannii in a single specimen may be due to the low number of $H$. marginatum specimens collected $(n=2)$. This pathogen was also found in $H$. lusitanicum from Sicily [57]. The pathogenicity of this bacterium to humans remains largely unknown, albeit the onset of MSF-like lesions has been suggested [58].

Surprisingly, Rickettsia conorii, the agent of MSF, was not detected in any of the Rhipicephalus spp. ticks examined in this study, probably due to the very low prevalence of the infection in nature [59]. Nonetheless, a recent study determined that several pathogenic Rickettsia spp. may be much more prevalent than $R$. conorii [60]. For example, $R$. massiliae was more prevalent than $R$. conorii (3.6\% vs. $1.3 \%$ ) in ticks removed from dogs in southern Italy [61] and a retrospective study of 24 human cases of spotted fever from Sicily confirmed infection by $R$. conorii subsp. israeliensis in five (20.8\%) and $R$. conorii subsp. conorii in 19 (79.2\%) cases, respectively [62].

Undoubtedly, knowledge on the pathogenic role of rickettsial species increases with the availability of scientific data on their aetiology and distribution. Consequently, the pathogenicity of $R$. rhipicephali detected in $R h$. turanicus from Sicily is yet to be determined. To the best of our knowledge, $R$. peacockii has been herein reported for the first time in Italy, and for the first time associated with $D$. marginatus, in Europe, as confirmed by the sequencing of three genes. This bacterium, originally found within the interstitial cells of the ovaries and oocytes of Dermacentor andersoni in the United States [63], was previously correlated with a reduced prevalence of $R$. rickettsii infection, the agent of Rocky Mountain spotted fever [64]. Remarkably, the presence of $R$. peacockii or a very closely related rickettsia in Europe should be examined with caution. Indeed, although the high genetic similarity between the $R$. peacockii sequences obtained herein and other sequences available in Genbank, the existence of a closely related but different endosymbiont of ticks in Europe cannot be excluded.

Other members of the family Anaplasmataceae were prevalent in ticks herein examined, and therefore may represent a risk to humans throughout the country. For example, results of this study confirm the occurrence of $C . \mathrm{N}$. mikurensis and A. phagocytophilum in I. ricinus from northeastern and northwestern Italy. Candidatus Neoehrlichia mikurensis is an obligate intracellular bacterium, isolated for the first time in rats (Rattus norvegicus) and in Ixodes ovatus ticks from Mikura Island, Japan [65]. However, a retrospective investigation of museum-archived $I$. ricinus female ticks, collected in Moldova in 1960, indicated that this pathogen has remained undetected for rather a long time [66]. Recently,
C. N. mikurensis has been identified throughout Europe and has been suggested as a causative agent of disease, mainly in immune-compromised patients from Europe [67] and China [68]. Conversely, A. phagocytophilum causes granulocytic anaplasmosis in humans and domestic animals, although it may also infect wild animals (e.g., red deer, roe deer, rodents, and hedgehogs), which act as reservoir hosts [69]. Both $C$. N. mikurensis and $A$. phagocythophilum was detected in I. ricinus in Italy, with an overall infection rate in ticks of $10.5 \%$ and $1.6-19.9 \%$, respectively $[14,70-72]$. Therefore, results suggest that humans in Italy are most likely exposed to $I$. ricinus ticks infected by $C$. N. mikurensis and $A$. phagocytophilum by frequenting areas where this tick species occurs (e.g. forests, meadows, grasslands, etc.) [14]. Similarly, the risk for transmission of the aforementioned pathogens may also be high in urban parks $[69,73]$, where I. ricinus may be brought in by birds [26]. In addition, the role of the Northern white-breasted hedgehog (Erinaceus romanicus), living in urban parks of central Europe (e.g., Hungary [74]) should also be considered. Interestingly, these mammals may also serve as major maintenance hosts for Ixodes hexagonus [69]. Similarly, the European hedgehog (Erinaceus europeus) has been identified as reservoir host for B. burgdorferi s.l. genospecies, including B. afzelii [75], here detected in $I$. ricinus from northern Italy.

\section{Conclusions}

Data presented here indicate that humans bitten by ticks in Italy are at risk of infection by different pathogens. The occurrence of co-infected ixodids both in nature and in ticks removed from humans indicates that more than one pathogen may be transmitted by the same tick specimen, which may complicate the clinical presentation in humans during multiple infections. Therefore, physicians should be aware of TBDs and of the possible occurrence of atypical clinical presentations, mainly in areas where more than one pathogen has been detected in ticks.

\section{Competing interests}

The authors declare that they have no competing interests.

\section{Authors' contributions}

DO, GC and FDT conceived and designed the experiments. AC, MTM, GC, DO and SAZ collected tick specimens. FDT, AG, MTM and FM performed the morphological identification. SR, SC, GC and MSL molecularly identified pathogens. DO, GC, AG, FDT, AC, MTM and SR wrote the first draft. All authors read and approved the final manuscript.

\section{Acknowledgments}

Authors thank Egidio Mallia (Parco delle Piccole Dolomiti Lucane, Italy), Riccardo Paolo Lia (University of Bari, Italy) for their support during the fieldwork, as well as the two unknown reviewers who strongly ameliorated the manuscript by their valuable suggestions. This study was conducted under the frame of the EurNegVec COST Action TD1303. Thanks Bayer Animal Health $\mathrm{GmbH}$, Leverkusen, Germany for covering the publication fee. 


\section{Author details}

${ }^{1}$ Department of Veterinary Medicine, University of Bari, 70010 Valenzano, Bari, Italy. ${ }^{2}$ Department of Immunology, Centro de Pesquisas Aggeu Magalhães (Fiocruz-PE), 50670-420 Recife, Pernambuco, Brazil. ${ }^{3}$ Department of Human Pathology, University of Messina, 98125 Messina, Italy. ${ }^{4}$ Istituto Zooprofilattico Sperimentale delle Venezie, 35020 Legnaro, Padova, Italy. ${ }^{5}$ Department of Veterinary Science and Public Health, University of Milan, 20133 Milan, Italy.

Received: 12 May 2014 Accepted: 29 June 2014

Published: 14 July 2014

\section{References}

1. Dantas-Torres F, Chomel BB, Otranto D: Ticks and tick-borne diseases: a One Health perspective. Trends Parasitol 2012, 28:437-446.

2. Estrada-Peña A, Ayllón N, de la Fuente J: Impact of climate trends on tick-borne pathogen transmission. Front Physiol 2012, 3:64

3. Jaenson TG, Eisen L, Comstedt P, Mejlon HA, Lindgren E, Bergström S, Olsen B: Risk indicators for the tick Ixodes ricinus and Borrelia burgdorferi sensu lato in Sweden. Med Vet Entomol 2009, 23:226-237.

4. Medlock JM, Hansford KM, Bormane A, Derdakova M, Estrada-Peña A, George JC, Golovljova I, Jaenson TG, Jensen JK, Jensen PM, Kazimirova M, Oteo JA, Papa A, Pfister K, Plantard O, Randolph SE, Rizzoli A, Santos-Silva MM, Sprong H, Vial L, Hendrickx G, Zeller H, Van Bortel W: Driving forces for changes in geographical distribution of Ixodes ricinus ticks in Europe. Parasit Vectors 2013, 6:1.

5. de la Fuente J, Kocan KM, Almazan C, Blouin EF: Targeting the tick-pathogen interface for novel control strategies. Front Biosci 2008, 13:6947-6956.

6. ECDC Meeting report: Second expert consultation on tick-borne diseases with emphasis on Lyme borreliosis and tick-borne encephalitis Stockholm, Sweden, 22-23 November 2011. available at: http://www. ecdc.europa.eu/en/publications/Publications/Tick-borne-diseases-meetingreport.pdf.

7. Manilla G: Fauna d'Italia. Acari-Ixodida. Bologna: Ed. Calderini; 1998

8. Santos-Silva MM, Beati L, Santos AS, De Sousa R, Núncio MS, Melo P, SantosReis M, Fonseca C, Formosinho P, Vilela C, Bacellar F: The hard-tick fauna of mainland Portugal (Acari: Ixodidae): an update on geographical distribution and known associations with hosts and pathogens. Exp Appl Acarol 2011. 55:85-121.

9. Scharlemann JP, Johnson PJ, Smith AA, Macdonald DW, Randolph SE: Trends in ixodid tick abundance and distribution in Great Britain. Med Vet Entomol 2008, 22:238-247.

10. Smith FD, Ballantyne R, Morgan ER, Wall R: Prevalence, distribution and risk associated with tick infestation of dogs in Great Britain. Med Vet Entomol 2011, 25:377-384

11. Dantas-Torres F, Otranto D: Species diversity and abundance of ticks in three habitats in southern Italy. Ticks Tick Borne Dis 2013, 4:251-255.

12. Curioni V, Cerquetella S, Scuppa P, Pasqualini L, Beninati T, Favia G: Lyme disease and babesiosis: preliminary findings on the transmission risk in highly frequented areas of the Monti Sibillini National Park (Central Italy). Vector Borne Zoonotic Dis 2004, 4:214-220.

13. Maioli G, Pistone D, Bonilauri P, Pajoro M, Barbieri I, Mulatto P, Vicari N, Dottori M: Etiological agents of rickettsiosis and anaplasmosis in ticks collected in Emilia-Romagna region (Italy) during 2008 and 2009. Exp Appl Acarol 2012, 57:199-208.

14. Capelli G, Ravagnan S, Montarsi F, Ciocchetta S, Cazzin S, Porcellato E, Babiker AM, Cassini R, Salviato A, Cattoli G, Otranto D: Occurrence and identification of risk areas of Ixodes ricinus-borne pathogens: a cost-effectiveness analysis in north-eastern Italy. Parasit Vectors 2012, 5:61.

15. Walker JB, Keirans JE, Horak IG: The Genus Rhipicephalus (Acari, Ixodidae): A Guide to the Brown Ticks of the World. Cambridge: Cambridge University Press; 2000.

16. Courtney JW, Kostelnik LM, Zeidner NS, Massung RF: Multiplex real-time PCR for detection of Anaplasma phagocytophilum and Borrelia burgdorferi. J Clinical Microbiol 2004, 42:3164-3168.

17. Massung RF, Slater KG: Comparison of PCR assays for detection of the agent of human granulocytic ehrlichiosis, Anaplasma phagocytophilum. J Clin Microbiol 2003, 41:717-722

18. Casati S, Sager H, Gern L, Piffaretti JC: Presence of potentially pathogenic Babesia sp. for human in Ixodes ricinus in Switzerland. Ann Agric Environ Med 2006, 13:65-70.
19. Skotarczak B, Wodecka B, Cichocka A: Coexistence DNA of Borrelia burgdorferi sensu lato and Babesia microti in Ixodes ricinus ticks from north-western Poland. Ann Agric Environ Med 2002, 9:25-28.

20. Jahfari S, Fonville M, Hengeveld P, Reusken C, Scholte EJ, Takken W, Heyman P, Medlock J, Heylen D, Kleve J, Sprong H: Prevalence of Neoehrlichia mikurensis in ticks and rodents from North-west Europe. Parasit Vectors 2012, 5:74

21. Diniz PP, Schulz BS, Hartmann K, Breitschwerdt EB: Candidatus Neoehrlichia mikurensis infection in a dog from Germany. J Clin Microbiol 2011, 49:2059.

22. Labruna MB1, Whitworth T, Bouyer DH, McBride J, Camargo LM, Camargo EP, Popov V, Walker DH: Rickettsia bellii and Rickettsia amblyommii in Amblyomma ticks from the state of Rondonia, Western Amazon, Brazil. J Med Entomol 2004, 41:1073-1081.

23. Márquez FJ, Muniain MA, Soriquer RC, Izquierdo G, Rodríguez-Baño J, Borobio MV: Genotypic identification of an undescribed spotted fever group Rickettsia in Ixodes ricinus from southwestern Spain. Am J Trop Med Hyg 1998, 58:570-577.

24. Regnery RL, Spruill CL, Plikaytis BD: Genotypic identification of rickettsiae and estimation of intraspecies sequence divergence for portions of two rickettsial genes. J Bacteriol 1991, 173:1576-1589.

25. Choi YJ, Jang WJ, Ryu JS, Lee SH, Park KH, Paik HS, Koh YS, Choi MS, Kim IS: Spotted fever group and Typhus Group Rickettsioses in Humans, South Korea. Emerg Infect Dis 2005, 11:237-244.

26. Uspensky l: Tick pests and vectors (Acari: Ixodoidea) in European towns: Introduction, persistence and management. Ticks Tick Borne Dis 2014, 5:41-47.

27. Otranto D, Capelli G, Genchi C: Changing distribution patterns of canine vector borne diseases in Italy: leishmaniosis vs. dirofilariosis. Parasit Vectors 2009, 1:S2.

28. Sanogo YO, Parola P, Shpynov S, Camicas JL, Brouqui P, Caruso G, Raoult D: Genetic diversity of bacterial agents detected in ticks removed from asymptomatic patients in northeastern Italy. Ann N Y Acad Sci 2003, 990:182-190.

29. Tagliapietra V, Rosà R, Arnoldi D, Cagnacci F, Capelli G, Montarsi F, Hauffe HC, Rizzoli A: Saturation deficit and deer density affect questing activity and local abundance of Ixodes ricinus (Acari, Ixodidae) in Italy. Vet Parasitol 2011, 183:114-124

30. Dantas-Torres F: Biology and ecology of the brown dog tick Rhipicephalus sanguineus. Parasit Vectors 2010, 3:26.

31. Parola P, Socolovschi C, Jeanjean L, Bitam I, Fournier PE, Sotto A, Labauge P, Raoult D: Warmer weather linked to tick attack and emergence of severe rickettsioses. PLoS Negl Trop Dis 2008, 2:e338.

32. Yesilbag K, Aydin L, Dincer E, Alpay G, Girisgin AO, Tuncer P, Ozkul A: Tick survey and detection of Crimean-Congo hemorrhagic fever virus in tick species from a non-endemic area, South Marmara region, Turkey. Exp Appl Acarol 2013, 60:253-261

33. Orkun O, Karaer Z, Cakmak A, Nalbantoğlu S: Spotted fever group rickettsiae in ticks in Turkey. Ticks Tick Borne Dis 2014, 5:213-218.

34. Mejlon HA, Jaenson TGT: Questing behaviour of Ixodes ricinus ticks (Acari: Ixodidae). Exp Appl Acarol 1997, 21:747-754.

35. McCoy KD, Léger $E$, Dietrich M: Host specialization in ticks and transmission of tick-borne diseases: a review. Front Cell Infect Microbiol 2013, 3:57.

36. Wilhelmsson $P$, Lindblom P, Fryland L, Nyman D, Jaenson TG, Forsberg P, Lindgren PE: Ixodes ricinus ticks removed from humans in Northern Europe: seasonal pattern of infestation, attachment sites and duration of feeding. Parasit Vectors 2013, 6:362.

37. Aktas M: A survey of ixodid tick species and molecular identification of tick-borne pathogens. Vet Parasitol 2014, 200:276-283.

38. Ciceroni L, Pinto A, Ciarrocchi S, Ciervo A: Current knowledge of rickettsial diseases in Italy. Ann NY Acad Sci 2006, 1078:143-149.

39. Mura A, Masala G, Tola S, Satta G, Fois F, Piras P, Rolain JM, Raoult D, Parola P. First direct detection of rickettsial pathogens and a new rickettsia, 'Candidatus Rickettsia barbariae', in ticks from Sardinia, Italy. Clin Microbiol Infect 2008, 14:1028-1033.

40. Oteo JA, Portillo A: Tick-borne rickettsioses in Europe. Ticks Tick Borne Dis 2012, 3:271-278.

41. Simser JA1, Palmer AT, Fingerle V, Wilske B, Kurtti TJ, Munderloh UG: Rickettsia monacensis sp. nov; a spotted fever group Rickettsia from ticks (Ixodes ricinus) collected in a European city park. Appl Environ Microbiol 2002, 68:4559-4566 
42. Floris R, Yurtman AN, Margoni EF, Mignozzi K, Boemo B, Altobelli A, Cinco M: Detection and identification of Rickettsia species in the northeast of Italy. Vector Borne Zoonotic Dis 2008, 8:777-782.

43. Jado I, Oteo JA, Aldámiz M, Gil H, Escudero R, Ibarra V, Portu J, Portillo A, Lezaun MJ, García-Amil C, Rodríguez-Moreno I, Anda P: Rickettsia monacensis and human disease, Spain. Emerg Infect Dis 2007, 13:1405-1407.

44. Vitale G, Mansueto S, Rolain JM, Raoult D: Rickettsia massiliae human isolation. Emerg Infect Dis 2006, 12:174-175.

45. Cascio A, Torina A, Valenzise M, Blanda V, Camarda N, Bombaci S, laria C De Luca F, Wasniewska M: Scalp eschar and neck lymphadenopathy caused by Rickettsia massiliae. Emerg Infect Dis 2013, 19:836-837.

46. Selmi M, Martello E, Bertolotti L, Bisanzio D, Tomassone L: Rickettsia slovaca and Rickettsia raoultii in Dermacentor marginatus ticks collected on wild boars in Tuscany, Italy. J Med Entomol 2009, 46:1490-1493.

47. Beninati T, Genchi C, Torina A, Caracappa S, Bandi C, Lo N: Rickettsiae in ixodid ticks, Sicily. Emerg Infect Dis 2005, 11:509-511

48. Torina A, Fernández de Mera IG, Alongi A, Mangold AJ, Blanda V, Scarlata F, Di Marco V, de la Fuente J: Rickettsia conorii Indian tick typhus strain and R. slovaca in humans, Sicily. Emerg Infect Dis 2012, 18:1008-1010.

49. Fournier PE, Allombert C, Supputamongkol Y, Caruso G, Brouqui P, Raoult D: Aneruptive fever associated with antibodies to Rickettsia helvetica in Europe and Thailand. J Clin Microbiol 2004, 42:816-818.

50. Santos-Silva MM, Sousa R, Santos AS, Melo P, Encarnação V, Bacellar F: Ticks parasitizing wild birds in Portugal: detection of Rickettsia aeschlimannii, R. helvetica and R. massiliae. Exp Appl Acarol 2006, 39:331-338.

51. Márquez FJ: Spotted fever group Rickettsia in ticks from southeastern Spain natural parks. Exp Appl Acarol 2008, 45:185-194.

52. Hornok S, Kováts D, Csörg T, Meli ML, Gönczi E, Hadnagy Z, Takács N, Farkas R, Hofmann-Lehmann R: Birds as potential reservoirs of tick-borne pathogens: first evidence of bacteraemia with Rickettsia helvetica. Parasit Vectors 2014, 7:128.

53. Beati L, Meskini M, Thiers B, Raoult D: Rickettsia aeschlimannii sp. nov., a new spotted fever group rickettsia associated with Hyalomma marginatum ticks. Int J Syst Bacteriol 1997, 47:548-554.

54. Raoult D, Fournier PE, Abboud P, Caron F: First documented human Rickettsia aeschlimannii infection. Emerg Infect Dis 2002, 8:748-749.

55. Parola P, Raoult D: Ticks and tick-borne bacterial diseases in humans: an emerging infectious threat. Clin Infect Dis 2001, 32:897-928.

56. Matsumoto K, Parola P, Brouqui P, Raoult D: Rickettsia aeschlimannii in Hyalomma ticks from Corsica. Eur J Clin Microbiol Infect Dis 2004, 23:732-734.

57. Torina A, Alongi A, Scimeca S, Vicente J, Caracappa S, de la Fuente J: Prevalence of tick-borne pathogens in ticks in Sicily. Transbound Emerg Dis 2010, 57:46-48.

58. Germanakis A, Chochlakis D, Angelakis E, Tselentis Y, Psaroulaki A: Rickettsia aeschlimannii infection in a man, Greece. Emerg Infect Dis 2012, 19:1176-1177

59. Parola P, Paddock CD, Raoult D: Tick borne rickettsioses around the world: emerging diseases challenging old concepts. Clin Microbiol Rev 2005 18:719-756.

60. Fernández-Soto P, Pérez-Sánchez R, Alamo-Sanz R, Encinas-Grandes A: Spotted fever group rickettsiae in ticks feeding on humans in northwestern Spain: is Rickettsia conorii vanishing? Ann N Y Acad Sci 2006, 1078:331-333.

61. Giammanco GM, Vitale G, Mansueto S, Capra G, Caleca MP, Ammatuna P: Presence of Rickettsia conorii subsp. israelensis, the causative agent of Israeli spotted fever, in Sicily, Italy, ascertained in a retrospective study. J Clin Microbiol 2005, 43:6027-6031.

62. Trotta M, Nicetto M, Fogliazza A, Montarsi F, Caldin M, Furlanello T, Solano-Gallego L: Detection of Leishmania infantum, Babesia canis, and rickettsiae in ticks removed from dogs living in Italy. Ticks Tick Borne Dis 2012, 3:294-297.

63. Niebylski ML, Schrumpf ME, Burgdorfer W, Fischer ER, Gage KL, Schwan TG: Rickettsia peacockii sp. nov., a new species infecting wood ticks, Dermacentor andersoni, in western Montana. Int J Syst Bacteriol 1997, 47:446-452

64. Felsheim RF, Kurtti TJ, Munderloh UG: Genome sequence of the endosymbiont Rickettsia peacockii and comparison with virulent Rickettsia rickettsii: identification of virulence factors. PLoS One 2009, 4:e8361.

65. Kawahara M, Rikihisa Y, Isogai E, Takahashi M, Misumi H, Suto C, Shibata S, Zhang C, Tsuji M: Ultrastructure and phylogenetic analysis of 'Candidatus
Neoehrlichia mikurensis' in the family Anaplasmataceae, isolated from wild rats and found in Ixodes ovatus ticks. Int I Syst Evol Microbiol 2004, 54:1837-1843

66. Movila A, Toderas I, Uspenskaia I, Conovalov J: Molecular detection of tick-borne pathogens in Ixodes ricinus from Moldova collected in 1960. Ticks Tick Borne Dis 2013, 4:359-361.

67. Maurer FP, Keller PM, Beuret C, Joha C, Achermann Y, Gubler J, Bircher D, Karrer U, Fehr J, Zimmerli L, Bloemberg GV: Close geographic association of human neoehrlichiosis and tick populations carrying "Candidatus Neoehrlichia mikurensis" in eastern Switzerland. J Clin Microbiol 2013, 51:169-176

68. Li H, Jiang JF, Liu W, Zheng YC, Huo QB, Tang K, Zuo SY, Liu K, Jiang BG, Yang H, Cao WC: Human infection with Candidatus Neoehrlichia mikurensis, China. Emerg Infect Dis 2012, 18:1636-1639.

69. Silaghi C, Skuballa J, Thiel C, Pfister K, Petney T, Pfäffle M, Taraschewski H, Passos LM: The European hedgehog (Erinaceus europaeus): a suitable reservoir for variants of Anaplasma phagocytophilum?. Ticks Tick Borne Dis 2012, 3:49-54

70. Aureli S, Foley JE, Galuppi R, Rejmanek D, Bonoli C, Tampieri MP: Anaplasma phagocytophilum in ticks from parks in the Emilia-Romagna region of northern Italy. Vet Ital 2012, 48:413-423.

71. Veronesi F, Galuppi R, Tampieri MP, Bonoli C, Mammoli R, Piergili Fioretti D: Prevalence of Anaplasma phagocytophilum in fallow deer (Dama dama) and feeding ticks from an Italy preserve. Res Vet Sci 2011, 90:40-43.

72. Mantelli B, Pecchioli E, Hauffe HC, Rosà R, Rizzoli A: Prevalence of Borrelia burgdorferi s.l. and Anaplasma phagocytophilum in the wood tick Ixodes ricinus in the Province of Trento, Italy. Eur J Clin Microbiol Infect Dis 2006, 25:737-739

73. Corrain R, Drigo M, Fenati M, Menandro ML, Mondin A, Pasotto D, Martini M: Study on ticks and tick-borne zoonoses in public parks in Italy. Zoonoses Public Health 2012, 59:468-476.

74. Földvári Földvári G, Jahfari S, Rigó K, Jablonszky M, Szekeres S, Majoros G, Tóth M, Molnár V, Coipan EC, Sprong H: Candidatus Neoehrlichia mikurensis and Anaplasma phagocytophilum in Urban Hedgehogs. Emerg Infect Dis 2014, 20:496-498.

75. Skuballa J, Petney T, Pfäffle M, Oehme R, Hartelt K, Fingerle V, Kimmig P, Taraschewski H: Occurrence of different Borrelia burgdorferi sensu lato genospecies including B. afzelii, B. bavariensis, and B. spielmanii in hedgehogs (Erinaceus spp.) in Europe. Ticks Tick Borne Dis 2012, 3:8-13.

doi:10.1186/1756-3305-7-328

Cite this article as: Otranto et al:: Ticks infesting humans in Italy and associated pathogens. Parasites \& Vectors 2014 7:328.

\section{Submit your next manuscript to BioMed Central and take full advantage of:}

- Convenient online submission

- Thorough peer review

- No space constraints or color figure charges

- Immediate publication on acceptance

- Inclusion in PubMed, CAS, Scopus and Google Scholar

- Research which is freely available for redistribution 